\title{
Effects of co-adsorbate and additive on the performance of dye-sensitized solar cells: A photophysical study
}

\author{
Kun-Mu Lee ${ }^{\mathrm{a}}$, Vembu Suryanarayanan ${ }^{\mathrm{b}}$, Kuo-Chuan $\mathrm{Ho}^{\mathrm{a}, \mathrm{b}, *}$, \\ K.R. Justin Thomas ${ }^{\mathrm{c}}$, Jiann T. $\operatorname{Lin}^{\mathrm{c}}$ \\ anstitute of Polymer Science and Engineering, National Taiwan University, Taipei 10617, Taiwan \\ ${ }^{\mathrm{b}}$ Department of Chemical Engineering, National Taiwan University, Taipei 10617, Taiwan \\ ${ }^{\mathrm{c} I n s t i t u t e}$ of Chemistry, Academia Sinica, 115 Nankang, Taipei, Taiwan
}

Available online 9 May 2007

\begin{abstract}
The effects of deoxycholic acid (DCA) in a dye solution as a co-adsorbate and guanidinium thiocyanate (GuSCN) in an electrolyte as an additive, on the photovoltaic performance of dye-sensitized solar cells (DSSCs) based on organic dye containing thiophene and fluorine segments (FL dye1) and black dye (BD) were investigated. The presence of DCA, up to 2 mM, increases both the photovoltage and photocurrent of the DSSC incorporating BD and further addition leads to decrease in the photocurrent. On the other hand, in the case of the DSSC containing FL dye1, the photocurrent decrease and photovoltage increase with the increase of DCA concentration. The pulsed laser measurement showed that electron lifetime $\left(\tau_{\mathrm{e}}\right)$ of $\mathrm{BD}$ is higher than that of $\mathrm{FL}$ dyel on a $\mathrm{TiO}_{2}$ electrode and the electron diffusion coefficient $\left(D_{\mathrm{e}}\right)$ of the latter is higher than that of the former where there is little deviation for both $\tau_{\mathrm{e}}$ and $D_{\mathrm{e}}$ with the addition of the DCA. The addition of GuSCN into electrolytes does enhance the photovoltage for DSSCs containing either FL dye1 or BD. This can be explained by the further adsorption of guanidinium cations following the dye adsorption that facilitates the self-assembly of dye molecules so as to either reduce the dark current or positively shift the conduction band edge of the $\mathrm{TiO}_{2}$. The value of $\tau_{\mathrm{e}}$ increases and the value of $D_{\mathrm{e}}$ decreases as a result of GuSCN addition.
\end{abstract}

(C) 2007 Elsevier B.V. All rights reserved.

Keywords: Dye-sensitized solar cells; Additive; Co-adsorption; Electron transfer

\section{Introduction}

Dye-sensitized solar cells (DSSCs), composed of a dyed oxide semiconductor, redox electrolyte and counter electrode, have proved themselves as the most promising lowcost alternative for the effective conversion of light energy into electrical energy [1]. In these devices, conversion efficiency is achieved by ultra-fast injection of an electron from a photoexcited dye into the conduction band of $\mathrm{TiO}_{2}$ and subsequently dye regeneration and holes transportation to the counter electrode.

\footnotetext{
${ }^{*}$ Corresponding author. Department of Chemical Engineering, National Taiwan University, Taipei 10617, Taiwan. Tel.: + 886223660739 ; fax: +886223623040 .

E-mail address: kcho@ntu.edu.tw (K.-C. Ho).
}

To improve the performance of the DSSC, several kinds of additives have been added into dye solutions. For example, Kay and Grätzel [2] found that the addition of cholic acid (CA) with porphyrin derivatives improved both the photocurrent and photovoltage of the solar cell. Further, other co-adsorbates such as hexadecylmalonic acid (HDMA) [3], 1-decyl phosphonic acid (DPA) [4] and 3-phenylpropionic acid (PPA) [5] were used with sensitizer onto nanocrystalline $\mathrm{TiO}_{2}$ film. Co-grafting of the two amphiphiles will result in the formation of mixed monolayer which should be more tightly packed than when the sensitizer is adsorbed alone, providing a more effective insulated barrier for the back electron transfers from $\mathrm{TiO}_{2}$ conduction band to triiodide electrolyte [3-6]. Such unwanted redox process is retarded by the hydrophobic spacer and as a result, the dark current is reduced producing high $V_{\text {OC. }}$. Moreover, guanidinium thiocyanate 

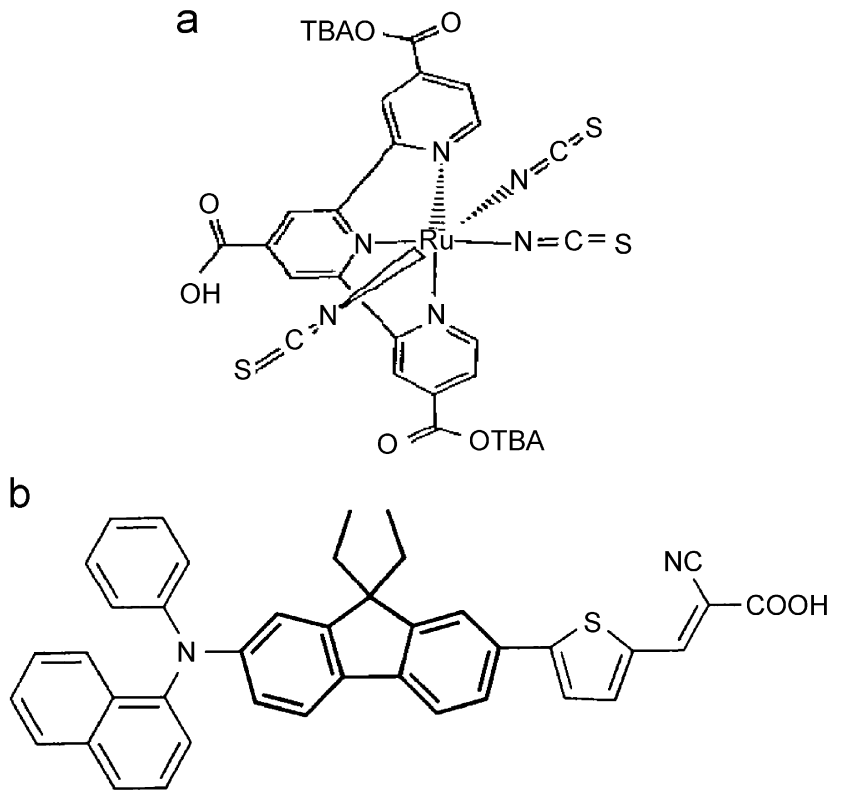

Scheme 1. Chemical structures of (a) BD and (b) FL dye1.

(GuSCN) has been also used as additive in organic electrolytes $[7,8]$, as it remarkably improves the photovoltage of solar cell due to reduction in the dark current, and increases the conversion efficiency of about $11 \%$ [7].

Detailed studies on the solar performance, spectroscopic measurements and electron transfer kinetics of DSSCs based on black dye (BD) (Scheme 1a) have been reported [9]. Recently, we constructed highly efficient DSSCs based on FL dyel containing thiophene and fluorine segments (Scheme 1b), and good solar energy-to-electricity conversion efficiency was achieved (5.23\%) under simulated AM $1.5\left(100 \mathrm{~mW} / \mathrm{cm}^{2}\right)$ light energy source [10]. Based on these reports, the influences of deoxycholic acid (DCA) as a coadsorbate in the dye solution and GuSCN as an additive in the electrolyte were investigated on the solar cell performance along with FL dye1 and BD.

\section{Experimental}

Anhydrous LiI, $\mathrm{I}_{2}$, poly(ethylene glycol) (PEG), and 4tertiary butyl pyridine (TBP) were obtained from Merck. GuSCN, DCA and titanium (IV) isopropoxide (+98\%) were purchased from Acros and used as such. $\mathrm{CH}_{3} \mathrm{CN}$ and tertiary butanol were purchased from Merck and water molecules were removed by putting molecular sieves $(4 \AA)$ into the solvent. FL dyel was synthesized in the laboratory based on our previous report [10] and BD was the commercial product obtained from Solaronix S.A., Aubonne, Switzerland. 1-Methyl-3-propylimidazolium iodide (MPII) was synthesized and its purity was checked by ${ }^{1} \mathrm{H}$ NMR.

The preparation of $\mathrm{TiO}_{2}$ precursor and the electrode fabrication were carried out according to the procedures mentioned in literatures [8,9] except after autoclave treatment, where the solution was concentrated to
$13 \mathrm{wt} \%$ and PEG (M.W. 20,000) was added to the $\mathrm{TiO}_{2}$ paste to prevent the film from cracking during drying. The $\mathrm{TiO}_{2}$ paste was coated on a fluorine-doped tin oxide (FTO) glass plate $\left(R_{\mathrm{sh}}=25 \Omega\right.$ /square, Sinonar Corp., Hsinchu, Taiwan) using glass rod.

An active area of $0.25 \mathrm{~cm}^{2}$ was selected from sintered electrode and the electrodes were immersed in $3 \times 10^{-4} \mathrm{M}$ solution of either $\mathrm{BD}$ or FL dyel containing different concentrations of the DCA in acetonitrile and tertiary butanol (in the volume ratio of $1: 1)$ for $24 \mathrm{~h}$. Pt $(100 \mathrm{~nm}$ thick) sputtered on FTO glass was used as the counter electrode. The electrolytes was composed of $0.8 \mathrm{M} \mathrm{1-}$ methyl-3-propylimidazolium iodide (MPII) $/ 0.1 \mathrm{M} \mathrm{LiI/}$ $0.05 \mathrm{M} \mathrm{I}_{2} / 0.5 \mathrm{M}$ TBP in $\mathrm{CH}_{3} \mathrm{CN}$. GuSCN was added to the electrolyte for few studies.

The photoelectrochemical characterizations of the DSSCs were carried out by using an AM 1.5 simulated light radiation. The light source was a $450 \mathrm{~W}$ Xe lamp (Oriel, no. 6266) equipped with a water-based IR filter and AM 1.5 filter (Oriel, no. 81075). The photovoltage transients of assembled devices were recorded with a digital oscilloscope (LeCroy, model LT322). Pulsed laser excitation was applied by a frequency-doubled Q-switched Nd:YAG laser (Spectra-Physics laser, model Quanta-Ray GCR-3-10) with $2 \mathrm{~Hz}$ repetition rate at 355 and $532 \mathrm{~nm}$, and $7 \mathrm{~ns}$ pulse width at half height. The beam size was slightly larger than $0.25 \mathrm{~cm}^{2}$ to cover the area of the device with an incident energy of $1 \mathrm{~mJ} / \mathrm{cm}^{2}$. The average electron lifetime can be estimated approximately by fitting a decay of the open-circuit voltage transient with $\exp \left(-t / \tau_{\mathrm{e}}\right)$, where $t$ is the time and $\tau_{\mathrm{e}}$ is an average time constant before recombination. Diffusion coefficient of electron was estimated by fitting a decay of the current transient with $\exp \left(-t / \tau_{\mathrm{c}}\right)$ which was derived from the equation of continuity for electrons in the conduction band [11], where $t$ and $\tau_{\mathrm{c}}$ are the time and average time constant, respectively. Then, the apparent diffusion coefficient of electron can be estimated using the equation

$D_{\mathrm{e}}=\frac{w^{2}}{2.35 \tau_{\mathrm{c}}}$,

where $w$ is the film thickness and the factor 2.35 arises from the geometry of the diffusion problem.

UV-vis absorption data was measured by UV-vis spectra (Jasco, V-570). Photoelectrochemical characteristics and the AC-impedance measurements of the DSSCs were recorded with a potentiostat/galvanostat (PGSTAT 30, Autolab, Eco-Chemie, The Netherlands) under constant light illumination of $100 \mathrm{~mW} / \mathrm{cm}^{2}$. The applied bias voltage and $\mathrm{AC}$ amplitude were set at open-circuit voltage of the DSSCs at $10 \mathrm{mV}$ between the FTO-Pt counter electrode and the $\mathrm{FTO}-\mathrm{TiO}_{2}$-dye working electrode, respectively, starting from the short-circuit condition and the frequency range explored was $10 \mathrm{mHz}-65 \mathrm{kHz}$. The impedance spectra were analyzed by an equivalent circuit model interpreting the characteristics of the DSSCs [12]. 


\section{Results and discussion}

UV-vis spectra of (a) BD and (b) FL dyel adsorbed on $\mathrm{TiO}_{2}$ photoanode at various concentrations of DCA are shown in Fig. 1. For BD without DCA, the absorption peaks at $330-340 \mathrm{~nm}$ were assigned to the $\pi-\pi^{*}$ absorption band. In Fig. 1a, two metal-to-ligand charge transfer (MLCT) transition bands were observed at 417 and $617 \mathrm{~nm}$, as reported in previous literature [9]. The single absorption peak observed for FL dye1 in Fig. 1b may be associated with $\pi-\pi^{*}$ charge transfer transition [10]. With the additions of DCA on both dyes adsorbed on the $\mathrm{TiO}_{2}$ electrode, no shift in absorption peak was observed; however the absorption maxima on $\mathrm{TiO}_{2}$ surface decreased with increasing concentration of the DCA. A decrease of about $60 \%$ and $30 \%$ of absorption was observed for the increase in the DCA concentrations of 20 and $30 \mathrm{mM}$, respectively, for both $\mathrm{BD}$ and FL dyel (Fig. 1a and b). The co-adsorbate DCA, like the dye, is able to adsorb on the $\mathrm{TiO}_{2}$ surface through the carboxyl group. The co-adsorption of the DCA would decrease the amount of adsorbed dye on the $\mathrm{TiO}_{2}$ surface. Strong interaction between the adsorbed dye molecules and the oxide molecules in the $\mathrm{TiO}_{2}$ surface leads to aggregate formation [13] and consequently, broadening of the absorption spectrum was observed during the dye absorption. This might be correlated with dye- $\mathrm{TiO}_{2}$ interactions, dye-dye interactions, or both, and co-adsorption of DCA diminished these interactions on the $\mathrm{TiO}_{2}$ surface $[14,15]$.

The photovoltaic performances of DSSCs based on BD and FL dye 1 under AM 1.5 irradiation $\left(100 \mathrm{~mW} / \mathrm{cm}^{2}\right)$ at various DCA concentrations were summarized in Table 1. For DSSCs made with BD and DCA co-absorbate, with increase in the DCA concentration, open-circuit voltage

a

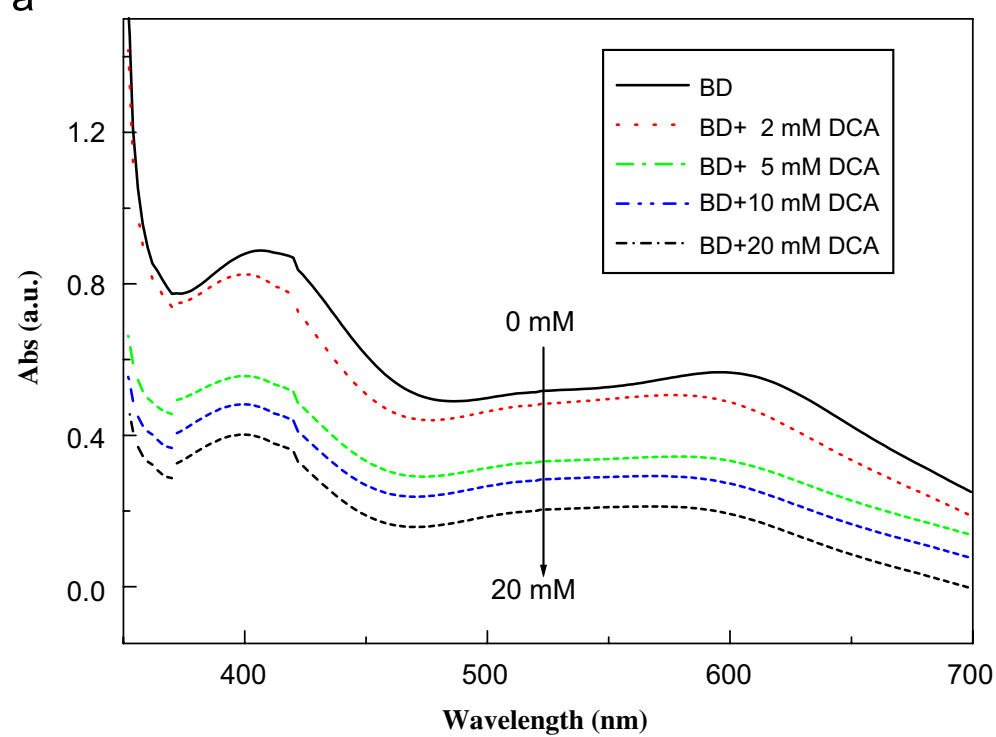

b

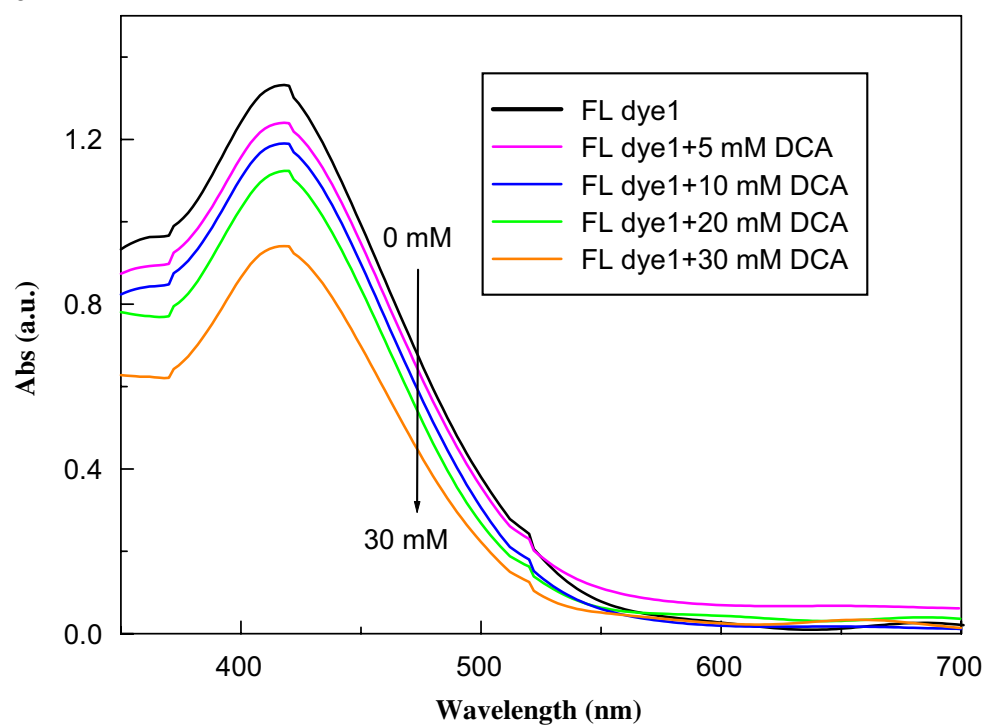

Fig. 1. The absorption spectra of (a) $\mathrm{BD}$ adsorbed on a $5 \mu \mathrm{m} \mathrm{TiO}_{2}$ film and (b) $\mathrm{FL}$ dyel adsorbed on a $1 \mu \mathrm{m} \mathrm{TiO}_{2}$ film. 
Table 1

The photovoltaic performance of the DSSCs based on BD and FL dyel containing different concentrations of DCA

\begin{tabular}{|c|c|c|c|c|c|c|}
\hline Sample no. & Dye & $\begin{array}{l}\text { Concentration of DCA in dye } \\
\text { solution }(\mathrm{mM})\end{array}$ & $J_{\mathrm{SC}}\left(\mathrm{mA} / \mathrm{cm}^{2}\right)$ & $V_{\mathrm{OC}}(\mathrm{V})$ & $\eta(\%)$ & $\mathrm{FF}$ \\
\hline 1 & \multirow[t]{4}{*}{ FL dyel } & 0 & 16.96 & 0.689 & 7.18 & 0.615 \\
\hline 3 & & 10 & 14.24 & 0.723 & 6.80 & 0.660 \\
\hline 4 & & 20 & 13.52 & 0.723 & 6.38 & 0.650 \\
\hline 5 & & 30 & 12.16 & 0.747 & 6.17 & 0.679 \\
\hline 8 & \multirow{3}{*}{$\mathrm{BD}$} & 5 & 9.28 & 0.671 & 4.09 & 0.657 \\
\hline 9 & & 10 & 9.68 & 0.677 & 4.48 & 0.684 \\
\hline 10 & & 20 & 8.00 & 0.689 & 3.87 & 0.702 \\
\hline 11 & w/o dye & 20 & 0.34 & 0.585 & 0.12 & 0.587 \\
\hline 12 & bare $\mathrm{TiO}_{2}$ & - & 0.31 & 0.463 & 0.07 & 0.483 \\
\hline
\end{tabular}

a

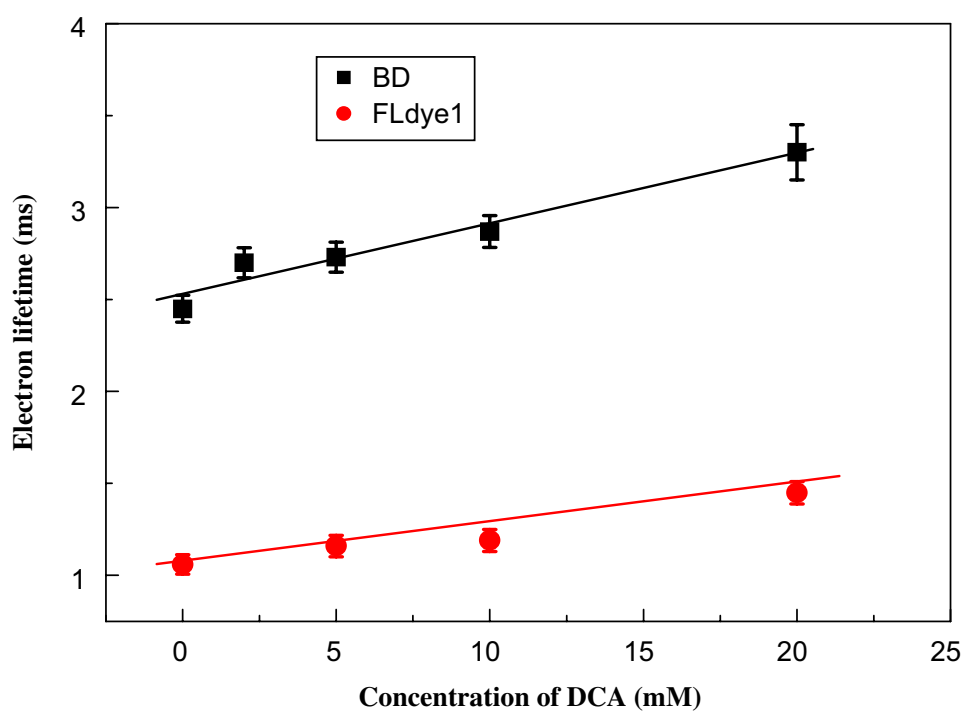

b

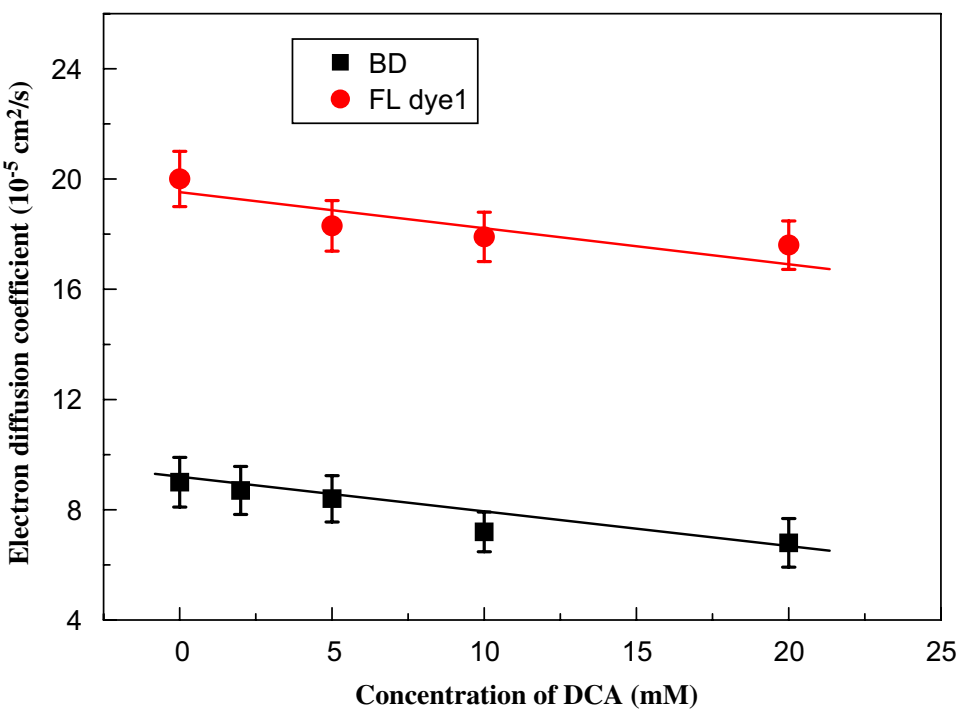

Fig. 2. Plots of (a) the lifetime and (b) the diffusion coefficient of electron on the $\mathrm{TiO}_{2}$ vs. different concentrations of the DCA in both $\mathrm{BD}$ and $\mathrm{FL}$ dye1. 
$\left(V_{\mathrm{OC}}\right)$ improved very well (for the addition from 0 to $20 \mathrm{mM}$ of DCA, the $V_{\mathrm{OC}}$ increased from 0.63 to $0.69 \mathrm{~V}$ ). Short-circuit current density $\left(J_{\mathrm{SC}}\right)$ increased slightly with $2 \mathrm{mM}$ of DCA and further increase in DCA concentration led to decrease in the $J_{\mathrm{SC}}$ value. The improvement in the photovoltage has to do with the suppression of the electron recombination between the injected electrons and $\mathrm{I}_{3}^{-}$ions on the $\mathrm{TiO}_{2}$ surfaces; while the photocurrent increases as the co-adsorbate reduces the dye aggregation either by suppressing the quenching processes of the energy transfer or shifting the conduction band edge of the $\mathrm{TiO}_{2}$ films positively. A different trend in the photovoltaic properties had been observed for the DSSCs based on FL dyel and DCA co-absorbate, where the $J_{\mathrm{SC}}$ values decreased and the $V_{\mathrm{OC}}$ improved with the increase in the concentration of DCA (Table 1).

We had also compared the cell performance of the DSSCs based on bare $\mathrm{TiO}_{2}$ (sample no. 12) and DCA anchored $\mathrm{TiO}_{2}$ without incorporating dye molecules (sample no. 11) and found that the $J_{\mathrm{SC}}, V_{\mathrm{OC}}$ and fill factor (FF) were higher for the latter $\left(0.34 \mathrm{~mA} / \mathrm{cm}^{2}, 0.585 \mathrm{~V}\right.$, and $0.587)$ when compared to the former $\left(0.31 \mathrm{~mA} / \mathrm{cm}^{2}\right.$, $0.463 \mathrm{~V}$, and 0.483 ) (Table 1). This indicates that adsorption of the DCA obviously increases the value of both the $V_{\mathrm{OC}}$ and FF in the DSSC.

Table 2

The effect of addition of GuSCN in the electrolyte on the photovoltaic performance of the DSSC $(\mathrm{GuSCN}=0.2 \mathrm{M})$

\begin{tabular}{|c|c|c|c|c|c|}
\hline Sample no. & Dye & $J_{\mathrm{SC}}\left(\mathrm{mA} / \mathrm{cm}^{2}\right)$ & $V_{\mathrm{OC}}(\mathrm{V})$ & $\eta(\%)$ & $\mathrm{FF}$ \\
\hline $1^{\prime}$ & FL dyel only & 9.52 & 0.755 & 4.69 & 0.650 \\
\hline $2^{\prime}$ & FL dye $1+5 \mathrm{mM}$ DCA & 9.40 & 0.791 & 5.32 & 0.715 \\
\hline $3^{\prime}$ & BD only & 8.00 & 0.725 & 4.12 & 0.710 \\
\hline $4^{\prime}$ & $\mathrm{BD}+2 \mathrm{mM} \mathrm{DCA}$ & 8.20 & 0.755 & 4.41 & 0.712 \\
\hline
\end{tabular}

Laser pulse-induced photovoltage transients were recorded for different concentrations of the DCA (coadsorbed) on the $\mathrm{TiO}_{2}$ electrode and the resultant electron lifetime $\left(\tau_{\mathrm{e}}\right)$ and electron diffusion coefficient $\left(D_{\mathrm{e}}\right)$ for BD and FL dye 1 are shown in Fig. $2 \mathrm{a}$ and $\mathrm{b}$, respectively. The $\tau_{\mathrm{e}}$ of $\mathrm{BD}$ was higher than that of FL dye1 in all concentrations of the DCA and it increased slightly with increase in the concentration of the DCA for both the dyes (Fig. 2a). On the other hand, the electron diffusion coefficient $\left(D_{\mathrm{e}}\right)$ in the $\mathrm{TiO}_{2}$ electrode is higher for $\mathrm{FL}$ dye1 than that of BD (Fig. 2b).

The effect of GuSCN as additive on the photovoltaic performance of the DSSC was first reported by Grätzel $[7,16]$. It was concluded that co-adsorption of GuSCN with dyes such as $\mathrm{N} 719$ and $\mathrm{N} 3$ improved the $V_{\mathrm{OC}}$ of the DSSC obviously due to the reduction of dark current [7]. In this study, we have also investigated the effect of addition of $0.2 \mathrm{M}$ of GuSCN in the same electrolyte and the results are shown in Table 2. The optimum concentrations of the DCA taken for this study with the BD and FL dyel were 2 and $5 \mathrm{mM}$, respectively, based on previous results (see Table 1). With the addition of $0.2 \mathrm{mM}$ of GuSCN, the $V_{\mathrm{OC}}$ showed a remarkable increase for the cell containing both the BD and FL dyel systems though the cell did not contain any DCA (compare sample nos. 1 and 6 in Table 1 with sample nos. $1^{\prime}$ and $3^{\prime}$ in Table 2). In the presence of DCA, the $V_{\mathrm{OC}}$ of the solar cell containing both the dyes was found to be very high (compare sample nos. 2 and 7 in Table 1 with sample nos. $2^{\prime}$ and $4^{\prime}$ in Table 2). This effect could be further confirmed from $I$ vs. $V$ curve obtained from the solar cell containing GuSCN without light (dark current) (Fig. 3). In this figure, the onset potential for the reduction of triiodide shows negative shift which indicates that the addition of GuSCN reduces the electron recombination between the $\mathrm{TiO}_{2}$ surface and $\mathrm{I}_{3}^{-}$[16]. Consequently, the enhancement of photovoltage by adding GuSCN as additive that not only

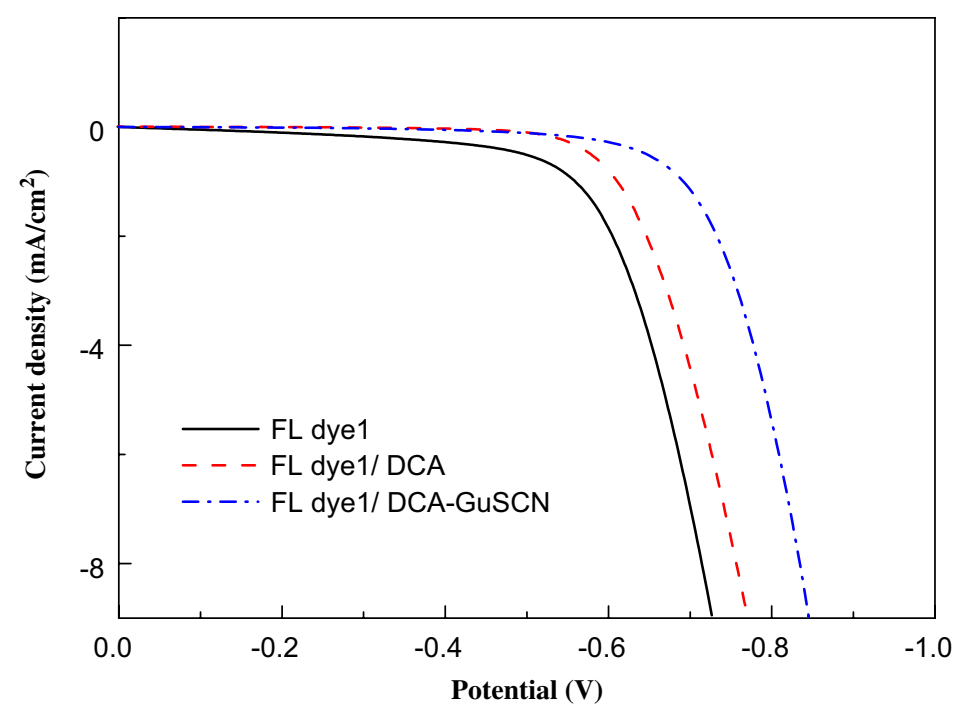

Fig. 3. The dark current observed from the $I$ vs. $V$ curve of the FL dyel-sensitized DSSC containing DCA in the absence and presence of GuSCN 
Table 3

Comparison of electron lifetime and electron diffusion coefficient on the $\mathrm{TiO}_{2}$ electrode containing DCA in the absence and presence of GuSCN

\begin{tabular}{lllll}
\hline & FL-a & FL-b & FL-c & FL-d \\
\hline$\tau_{\mathrm{e}}(\mathrm{ms})$ & 0.92 & 0.52 & 1.35 & 0.70 \\
$D_{\mathrm{e}}\left(\mathrm{cm}^{2} / \mathrm{s}\right)$ & $2.96 \times 10^{-5}$ & $5.32 \times 10^{-5}$ & $2.05 \times 10^{-5}$ & $3.13 \times 10^{-5}$ \\
\hline
\end{tabular}

FL-a: FL dyel only; FL-b: FL dye1+0.2M GuSCN; FL-c: FL dye1+0.5 M DCA; FL-d: FL dye1+0.2 M GuSCN+0.5 M DCA.

shield the surface against recombination but also shift the band edge to negative potential.

On the other hand, the $J_{\mathrm{SC}}$ as well as the cell efficiency of the DSSC was lower in the presence of the DCA and/or GuSCN than their absence (compare Tables 1 and 2). From Table 2, it is understandable that the addition of GuSCN in the electrolyte somehow decreases the efficiency of the solar cell slightly. Moreover, the efficiency of the solar cell with FL dyel was always higher than the BD irrespective of different additives. Hence, for further studies the effects of DCA and GuSCN on electron transport mechanism by laser pulse-induced transient photovoltage, FL dyel was alone taken and the results are shown in Table 3. The addition of GuSCN in the absence of the DCA increased the $D_{\mathrm{e}}$ and there was only little decrease in the electron lifetime $\left(\tau_{\mathrm{e}}\right)$. However, in the DCA co-adsorption system, although the DCA can increase the electron lifetime $\left(\tau_{\mathrm{e}}\right)$, the addition of the GuSCN in electrolyte decreases the electron lifetime $\left(\tau_{\mathrm{e}}\right)$ and increases the $D_{\text {e }}$ gently.

Consequently, it is noted that the addition of the DCA in dye solution and GuSCN in electrolyte increase the $V_{\mathrm{OC}}$ and lower the $J_{\mathrm{SC}}$ of the solar cell, whereas both behave differently in their electron transport on the $\mathrm{TiO}_{2}(\mathrm{DCA}$ increases the electron lifetimes and decrease the $D_{\mathrm{e}}$ and the GuSCN functions in vice versa).

\section{Conclusions}

The effect of addition of the DCA and GuSCN on the photovoltaic performance of the DSSCs based on the FL dyel and BD was studied. Small increase in the $V_{\mathrm{OC}}$ and $J_{\mathrm{SC}}$ of the DSSC based on the BD was noted with the addition of $2 \mathrm{mM}$ of the DCA and further addition increased the $V_{\mathrm{OC}}$ only. However, a decrease in the $J_{\mathrm{SC}}$ and increase in the $V_{\mathrm{OC}}$ of the DSSC was observed incorporating FL dyel for the addition of the DCA. The enhancement in the photovoltage may be correlated with the suppression of the electron recombination between the injected electrons and $\mathrm{I}_{3}^{-}$ions on the $\mathrm{TiO}_{2}$ surfaces. The pulsed laser measurement showed that $\tau_{\mathrm{e}}$ of the $\mathrm{BD}$ is higher than that of the FL dyel on the $\mathrm{TiO}_{2}$ electrode and the $D_{\mathrm{e}}$ of the later is higher than that of the former where there is little deviation for both $\tau_{\mathrm{e}}$ and $D_{\mathrm{e}}$ with the addition of the DCA. The addition of GuSCN into electrolytes enhances the photovoltage for the DSSCs containing either FL dye 1 or BD in which it increases $D_{\mathrm{e}}$ and decreases $\tau_{\mathrm{e}}$.

\section{Acknowledgments}

This work was financially supported by the Academia Sinica, Taipei, Taiwan, the Republic of China, under Grant AS-94-TP-A02. Helpful discussions with Professor Tien-Yau Luh, of Department of Chemistry, National Taiwan University, are appreciated. We also want to thank Professor King-Chuen Lin and his research group members of Department of Chemistry, National Taiwan University, for the help in making the pulsed laser apparatus available to us.

\section{References}

[1] B. O’Reagen, M. Grätzel, Nature 353 (1991) 373.

[2] A. Kay, M. Grätzel, J. Phys. Chem. 97 (1993) 6272.

[3] P. Wang, S.M. Zakeeruddin, P. Comte, R. Charvet, R. HumphryBaker, M. Grätzel, J. Phys. Chem. B 107 (2003) 14336.

[4] P. Wang, S.M. Zakeeruddin, R. Humphry-Baker, J.E. Moser, M. Grätzel, Adv. Mater. 15 (2003) 2101.

[5] P. Wang, S.M. Zakeeruddin, R. Humphry-Baker, M. Grätzel, Chem. Mater. 16 (2004) 2694.

[6] J. He, G. Benkö, F. Korodí, T. Polivka, R. Lomoth, B. Åkermark, L. Sun, A. Hagfeldt, V. Sundström, J. Am. Chem. Soc. 124 (2002) 4922.

[7] M. Grätzel, J. Photochem. Photobiol. A: Chem. 164 (2004) 3.

[8] Z.-S. Wang, K. Hara, Y. Dan-oh, C. Kasada, A. Shinpo, S. Suga, H. Arakawa, H. Sugihara, J. Phys. Chem. B 109 (2005) 3907.

[9] K. Hara, T. Nishikawa, M. Kurashige, H. Kawauchi, T. Kashima, K. Sayama, K. Aika, H. Arakawa, Sol. Energy. Mater. Sol. Cells 85 (2005) 21

[10] K.R. Justin Thomas, J.T. Lin, Y.-C. Hsu, K.-C. Ho, Chem. Commun. (2005) 4098.

[11] J. van de Lagemaat, A.J. Frank, J. Phys. Chem. B 105 (2001) 11194.

[12] C. Longo, J. Freitas, M.A. De Paoli, J. Photochem. Photobiol. A: Chem. 159 (2003) 33.

[13] M.C. Bernard, H. Cachet, P. Falaras, A. Hugot-Le Goff, M. Kalbac, I. Lukes, N.T. Oanh, T. Stergiopoulos, I. Arabatzis, J. Electrochem. Soc. 150 (2003) E155.

[14] P.V. Kamat, Chem. Rev. 93 (1993) 267.

[15] K. Hara, Y. Dan-oh, C. Kasada, Y. Ohga, A. Shinpo, S. Suga, K. Sayama, H. Arakawa, Langmuir 20 (2004) 4205.

[16] M. Grätzel, J. Photochem. Photobiol. C: Photochem. Rev. 4 (2003) 145 . 